\title{
Association of physical activity and sedentary lifestyle patterns with obesity and cardiometabolic comorbidities in Greek adults: Data from the National Epidemiological Survey
}

Maria Hassapidou, ${ }^{1,2}$ Sousana K. Papadopoulou, ${ }^{1,2}$ George Vlahavas, ${ }^{2}$ Efthymios Kapantais, ${ }^{1}$ Daphne Kaklamanou, ${ }^{1}$ Ioannis Pagkalos, ${ }^{3}$ Myrto Kaklamanou, ${ }^{1}$ Themistoklis Tzotzas ${ }^{1}$

${ }^{1}$ Hellenic Medical Association for Obesity (HMAO), Athens, ${ }^{2}$ Department of Nutrition and Dietetics, ATEI, Thessaloniki, ${ }^{3}$ Department of Electrical and Computer Engineering, Aristotle University of Thessaloniki, Thessaloniki, Greece

\begin{abstract}
OBJECTIVE: To investigate the association between physical activity (PA) and sedentary lifestyle (SL) patterns with overweight $(\mathrm{OW})$, obesity $(\mathrm{OB})$, abdominal obesity $(\mathrm{AO})$ and cardiometabolic comorbidities in Greek adults based on data from the National Epidemiological Survey for the prevalence of obesity. DESIGN: Cross-sectional epidemiological survey. Participants were selected via stratified sampling. 17,887 men and women, 20-70 years old, underwent anthropometric measurements for the estimation of $O W, O B$ and $A O$ prevalence. Assessment of PA, SL patterns and metabolic comorbidities was performed using an in-home questionnaire allowing self-evaluation of diverse activities and self-report for the presence of hypercholesterolemia (HCE), type 2 diabetes mellitus (T2DM) or hypertension (HTN). RESULTS: In men, even small amounts of walking were associated with decreased risk of being $O W$ and $A O$, while larger amounts were associated with decreased risk of being $O B$. In women, engagement in entertainment activities for more than 4 hours per week was associated with less risk of being OW. Concerning cardiometabolic comorbidities, substantial improvement was evident mainly for men, e.g. signfiicantly reduced risk for HCE, T2DM and HTN by frequent engagement in exercise. On the other hand, frequent TV watching and long hours of office work significantly increased the risk of HCE and HTN in men. CONCLUSIONS: In Greek adults, and men in particular, walking activity was significantly associated with lower risk for obesity. In addition, frequent exercise and less sedentary behaviour were associated with reduced risk for cardiometabolic factors, mainly hypercholesterolemia and hypertension.
\end{abstract}

Key words: Abdominal obesity, Greek adults, Metabolic comorbidities, Obesity, Physical activity, Prevalence 


\section{INTRODUCTION}

There is a worldwide increase in the prevalence of overweight (OW) and obese individuals (OB), with OB becoming a major public health problem. ${ }^{1}$ In developed as well as in developing societies, obesity predisposes to life-threatening chronic diseases, such as cardiovascular disease (CVD), type 2 diabetes mellitus (T2DM), hypertension (HTN), dyslipidemia and cancer, and thereby contributes to premature mortality. ${ }^{1,2}$ While genes may serve as predictors of obesity, there is, however, a strong environmental effect on the phenotypic expression of genes. Thus, subjects with genetic predisposition to obesity become obese only when exposed to an unhealthy lifestyle, including unwholesome diet and/or inactivity. ${ }^{3}$

Energy expenditure of $\sim 2000 \mathrm{Kcal}$ per week has been proposed as a contributor to longevity and a protective "shield" against CVD. ${ }^{4}$ Nevertheless, modernization, industrialization and the subsequent automatization of everyday life have considerably decreased manual work and have resulted in the overwhelming majority of people leading a sedentary way of life. Despite its apparent appeal, this lifestyle has brought about a detrimental reduction of energy expenditure. ${ }^{5} \mathrm{TV}$ watching has also been associated with obesity due not only to decreased energy expenditure but also to increased energy intake induced by the consumption of fat- and sugar-rich foods during this inactivity. ${ }^{6}$

By stark contrast, physical activity (PA) leads to a negative energy and fat balance, as it increases energy expenditure and, more specifically, fat oxidation, since it is well known that insufficient fat oxidation is correlated with obesity. Apart from prevention of obesity, exercise plays a crucial role in the prevention of cardiometabolic risk factors such as T2DM, dyslipidemia and HTN, and, as it has repeatedly been shown, cardiovascular disease. ${ }^{7}$ Intense aerobic exercise (such as fast walking, jogging, racket games, cycling or swimming) during leisure time has been found to protect against coronary heart disease (CHD) and heart attacks in middle- and old-aged subjects. ${ }^{7}$

The majority of recent studies shows that a high percentage of individuals living in developed societies adopt a sedentary lifestyle (SL). Nearly $30 \%$ of the English population ${ }^{3}$ reports little or no leisure-time physical activity, while the corresponding percentage in the USA amounts to 50\%. ${ }^{8}$ In Greece, during the last few decades, there has been a dramatic shift from manual work to non-manual office work. ${ }^{9}$ It has previously been reported that $50 \%$ of the Greeks who live in the prefecture of Attica were physically inactive, with men being more active than women. ${ }^{10}$ In a study across nine European countries, only $30 \%$ of women and $50 \%$ of men were active or moderately active. ${ }^{11}$ The aim of the present study was to examine the association between PA and SL patterns and the prevalence of overweight and obesity as well as their metabolic comorbidities, such as T2DM, hypercholesterolemia (HCE) and HTN in Greek adults. To the best of our knowledge, no study to date has examined these associations in an extended sample of a Greek population.

\section{SUBJECTS AND METHODS}

In this study, we analyzed data concerning physical activity patterns and metabolic comorbidities taken from the first nationwide cross-sectional epidemiological survey, conducted in 2003, for the prevalence of obesity in Greek adults. The survey was performed by experienced physicians, all members of the Hellenic Medical Association for Obesity (HMAO), with the approval and collaboration of the Greek Ministry of Education. The survey was approved by the ethics committee of the Technological Educational Institute of Thessaloniki (Ref. No 20102).

The methodology used in the study has been described in previous papers. ${ }^{12,13}$ Briefly, the selection of participants was conducted by proportionate stratified random sampling (SRS) through household family members of Greek adolescent (13-19yrs) students of public schools throughout the country. Each adolescent was provided with an envelope containing an in-home questionnaire for all household relatives. Adolescents received training on anthropometric techniques by physical training instructors, following standardized criteria, in order to be able to take measurements of their relatives at home. Therefore, their adolescent children measured most adult participants for obesity indices. Other subjects, such as young unmarried adults, aged 20-35 (uncles, aunts, older siblings), who lived in the same house, also took part. 
Anthropometric measurements included height, body weight, waist and hip circumference. Weight was measured to the nearest $0.1 \mathrm{~kg}$ with the same kind of portable scale (Terraillon T 715, Terraillon France, France) and the participant in minimal clothing. Height was measured to the nearest $0.1 \mathrm{~cm}$ without shoes. Body mass index (BMI) was calculated as body weight $(\mathrm{Kg})$ divided by squared height $\left(\mathrm{m}^{2}\right)$. Waist circumference (WC) was measured with a tape at the mid-distance between the top of the iliac crest and the bottom of the rib cage. BMI was categorized according to the World Health Organization ${ }^{2}$ standards: normal weight: $<25 \mathrm{~kg} / \mathrm{m}^{2}$, overweight: $25-29.9 \mathrm{~kg} /$ $\mathrm{m}^{2}$ and obese: $>30 \mathrm{~kg} / \mathrm{m}^{2}$. Abdominal obesity was defined as waist circumference more than $102 \mathrm{~cm}$ in men and $88 \mathrm{~cm}$ in women. ${ }^{14}$

All participants were invited to complete a selfreported questionnaire designed to assess PA and health status. Subjects were asked two types of questions in order to assess PA/exercise and SL levels on a weekly basis via:

a) self-assessment of the weekly amount of time spent on walking and organized exercise, i.e. in gyms or sport centers;

b) self-evaluation of the time spent on TV watching, working in an office or at a workplace requiring sedentary (sitting) time, as well as time spent for entertainment (going to a cinema, restaurant, café, bar).

In accordance with the associations established by Aadahl et al, ${ }^{15}$ walking and exercise were grouped into the following categories: $<2 \mathrm{~h} /$ week, $2-3.9 \mathrm{~h} /$ week, $4-6.9 \mathrm{~h} /$ week and $\geq 7 \mathrm{~h} /$ week.

Cardiometabolic health status was ascertained in all participants through self-reported physiciandiagnosed presence or absence of T2DM, HCE and HTN (Question asked: Have you ever been diagnosed by your physician as having diabetes, high cholesterol levels or high blood pressure?).

The non-response rate (including incorrect values) for the variables included in the analysis was as follows: Body Weight, 2.3\%; Height, 2.5\%; Waist Circumference, $4.6 \%$; PA patterns, $2.2 \%$; Presence of metabolic comorbidities, $2.5 \%$. From a total estimated number of 22,147 subjects, 17,887 adults were available for the final analysis (valid participation rate $80.76 \%$;
8,423 men and 9,464 women). The overall mean age and standard deviation ( \pm SD) was $43.4 \pm 19.1$ years (44.4 \pm 25 , for men; $41.3 \pm 11.5$ for women).

\section{Statistical Analysis}

Multiple binary logistic regression analyses were performed to determine the association between walking, exercise, TV watching, office work and entertainment and $\mathrm{OW}, \mathrm{OB}, \mathrm{AO}$ as well as various metabolic comorbidities. An independent sample ttest was performed to compare BMI results between genders. The odds ratios were calculated for all dependent factors using a confidence level of $95 \%$. Interactions between factors entered in the logistic regression models were also examined. Values of $\mathrm{p}<0.05$ were considered to be statistically significant. Statistical analyses were performed using Minitab v15.

\section{RESULTS}

The mean BMI of the total study population was $26.5 \pm 5.3$ and was higher in men than in women $(27.3 \pm 4.9 \mathrm{vs} 25.7 \pm 5.1, \mathrm{p}<0.001)$. The mean value of waist circumference was $90 \mathrm{~cm}$ ( $95.3 \mathrm{~cm}$ for men, 85.4 $\mathrm{cm}$ for women, $\mathrm{p}<0.001)$. The overall prevalence of OB was $22.3 \%$ (25.9\% in men, $19.2 \%$ in women), of OW $35.2 \%$ (41\% in men, $29.8 \%$ in women) and that of AO 26.9\% in men and $35.5 \%$ in women. More details of the sample's anthropometric characteristics have been reported in a previous publication. ${ }^{12}$ The most frequently reported metabolic disturbance of the study population was HCE (13.3\% overall, $12.6 \%$ in men, $8.2 \%$ in women), followed by HTN (8.6\% overall, $9.4 \%$ in men, $7.9 \%$ in women) and T2DM (4.2\% overall, $4.7 \%$ in men, $3.6 \%$ in women). Regarding PA parameters, almost $37 \%$ of subjects reported walking less than 2 hours/week and $90 \%$ of them exercised less than 2 hours/week. Additionally, more than $1 / 3$ of the study population reported that their entertainment time was longer than 4 hours/week. When practices of sedentary lifestyle were analyzed, $37.9 \%$ of the subjects (37.8\% of men, $37.9 \%$ of women) reported watching TV for more than 16 hours/week and $20.5 \%$ of the subjects $(24.5 \%$ of men, $16.9 \%$ of women) reported doing office work for more than 14 hours/ week. The prevalence of OB, AO, comorbidities and features of PA of the study population according to gender are presented in Table 1. 
Table 1. Prevalence of obesity, abdominal obesity, metabolic comorbidities and features of physical activity of the study population and according to gender

\begin{tabular}{|c|c|c|c|}
\hline & Total $(\%)$ & Males (\%) & Females (\%) \\
\hline \multicolumn{4}{|l|}{ Obesity status } \\
\hline Normal & 42.4 & 33.1 & 50.9 \\
\hline Overweight & 35.2 & 41.1 & 29.8 \\
\hline Obese & 22.3 & 25.9 & 19.2 \\
\hline \multicolumn{4}{|l|}{ Abdominal obesity } \\
\hline Absence & & 73.1 & 64.5 \\
\hline Presence & & 26.9 & 35.5 \\
\hline \multicolumn{4}{|l|}{ Comorbidities } \\
\hline Diabetes & 4.2 & 4.7 & 3.6 \\
\hline Hypercholesterolemia & 13.3 & 12.6 & 8.2 \\
\hline Hypertension & 8.6 & 9.4 & 7.9 \\
\hline \multicolumn{4}{|l|}{ Walking } \\
\hline$<2 \mathrm{hrs} /$ week & 36.9 & 37.4 & 36.6 \\
\hline $2-3.9 \mathrm{hrs} /$ week & 16.9 & 14.9 & 18.7 \\
\hline $4-6.9 \mathrm{hrs} /$ week & 13.8 & 12.1 & 15.3 \\
\hline$\geq 7 \mathrm{hrs} /$ week & 32.4 & 35.5 & 29.4 \\
\hline \multicolumn{4}{|l|}{ Exercise } \\
\hline$<2 \mathrm{hrs} /$ week & 90.3 & 91.3 & 89.4 \\
\hline $2-3.9 \mathrm{hrs} /$ week & 4.4 & 2.9 & 5.6 \\
\hline $4-6.9 \mathrm{hrs} /$ week & 3.3 & 3.3 & 3.4 \\
\hline$\geq 7 \mathrm{hrs} /$ week & 2.2 & 2.5 & 1.6 \\
\hline \multicolumn{4}{|l|}{ TV watching } \\
\hline$<16$ hrs/week & 62.1 & 62.2 & 62.1 \\
\hline$\geq 16$ hrs/week & 37.9 & 37.8 & 37.9 \\
\hline \multicolumn{4}{|l|}{ Office work } \\
\hline$<14 \mathrm{hrs} /$ week & 79.5 & 75.5 & 83.1 \\
\hline$\geq 14$ hrs/week & 20.5 & 24.5 & 16.9 \\
\hline \multicolumn{4}{|l|}{ Entertainment } \\
\hline$<4$ hrs/week & 66.3 & 59.3 & 72.6 \\
\hline$\geq 4 \mathrm{hrs} /$ week & 33.7 & 40.7 & 27.4 \\
\hline
\end{tabular}

In men, walking between 2 to 3.9 hours per week decreased the risk of OW and AO by $15 \%$ and $14 \%$, respectively $(\mathrm{p}<0.05)$. Moreover, walking for more than 7 hours per week decreased the likelihood of OB by $12 \%(\mathrm{p}<0.05)$. Exercise, entertainment, TV watching and office work were not found to be associated with $\mathrm{OW}, \mathrm{AO}$ or $\mathrm{OB}$. Table 2 presents the odds ratio of $\mathrm{OW}, \mathrm{OB}$ and $\mathrm{AO}$ by different $\mathrm{PA}$ patterns in men.
In women, entertainment for more than 4 hours per week decreased the risk of OW by $8 \%,(\mathrm{p}<0.05)$, while walking, exercise, TV watching and office work were not found to be associated with $\mathrm{OW}, \mathrm{AO}$ or OB (Table 3).

Table 4 shows the odds ratio of the reported presence of HCE, T2DM and HTN by different PA patterns and indices of sedentary lifestyle in men. Exercise for more than 7 hours per week decreased HCE risk by $55 \%(p<0.05)$. On the other hand, TV watching for more than 16 hours per week and office work longer than 14 hours per week increased the risk of HCE by $20 \%(\mathrm{p}<0.05)$ and $55 \%(\mathrm{p}<0.001)$, respectively. Concerning T2DM, we found that exercising between 4 to 6.9 hours/week decreased odds ratio $70 \%$ ( $\mathrm{p}<0.05)$. Walking, TV watching, office work and entertainment did not affect the risk of T2DM. Exercising between 4 to 6.9 hours/week reduced by half HTN presence $(\mathrm{p}<0.05)$. By contrast, TV watching for more than 16 hours per week and office work longer than 14 hours per week increased the risk of HTN by $36 \%(\mathrm{p}<0.001)$ and $33 \%(\mathrm{p}<0.05)$, respectively.

In women, PA patterns were not associated with any cardiometabolic risk factor (Table 5). TV watching alone, for more than 16 hours per week, increased the risk for HTN presence by $33 \%(\mathrm{p}<0.05)$. Additionally, office work, for more than 14 hours per week, appeared to decrease the likelihood of T2DM by $36 \%(\mathrm{p}<0.05)$.

\section{DISCUSSION}

This cross-sectional study is the first to report on the association of exercise and sedentary lifestyle patterns with $\mathrm{OB}$ and its metabolic comorbidities in an extended sample covering all the Greek territory. According to our findings, this applying only to men, even small amounts of walking were associated with decreased risk of being $\mathrm{OW}$ and $\mathrm{AO}$, while large amounts of walking were associated with decreased risk of being OB. In women, only engagement in entertainment activities for more than 4 hours per week was associated with decreased risk of being OW. Concerning cardiometabolic comorbidities, substantial improvements were evidenced mainly in men: risk for HCE,T2DM and HTN was significantly reduced by frequent exercise practices, while risk of 
Table 2. Odds ratio of overweight, obesity and abdominal obesity by different physical activity patterns in men

\begin{tabular}{|c|c|c|c|c|c|c|}
\hline \multirow[b]{2}{*}{ Predictor } & \multicolumn{2}{|c|}{ Overweight } & \multicolumn{2}{|l|}{ Obesity } & \multicolumn{2}{|c|}{ Abdominal obesity } \\
\hline & Odds Ratio (95\%CI) & $\mathbf{P}$ & Odds Ratio (95\%CI) & $\mathbf{P}$ & Odds Ratio (95\%CI) & $\mathbf{P}$ \\
\hline \multicolumn{7}{|l|}{ Age group } \\
\hline $18-39$ & 1.00 (Ref.) & & 1.00 (Ref.) & & 1.00 (Ref.) & \\
\hline $40-65$ & $1.96(1.70-2.26)$ & $<0.001$ & $1.68(1.44-1.96)$ & $<0.001$ & $2.20(1.93-2.51)$ & $<0.001$ \\
\hline$>65$ & $1.75(1.31-2.33)$ & $<0.001$ & $1.70(1.29-2.25)$ & $<0.001$ & $2.18(1.68-2.83)$ & $<0.001$ \\
\hline \multicolumn{7}{|l|}{ Walking } \\
\hline$<2 \mathrm{hrs} /$ week & 1.00 (Ref.) & & 1.00 (Ref.) & & 1.00 (Ref.) & \\
\hline $2-3.9 \mathrm{hrs} /$ week & $0.85(0.73-1.00)$ & 0.050 & $0.89(0.76-1.04)$ & 0.143 & $0.86(0.74-1.00)$ & 0.049 \\
\hline $4-6.9 \mathrm{hrs} /$ week & $0.96(0.81-1.15)$ & 0.663 & $0.92(0.78-1.09)$ & 0.338 & $0.95(0.81-1.12)$ & 0.562 \\
\hline$\geq 7 \mathrm{hrs} /$ week & $0.95(0.84-1.08)$ & 0.414 & $0.88(0.78-1.00)$ & 0.044 & $0.96(0.86-1.07)$ & 0.466 \\
\hline \multicolumn{7}{|l|}{ Exercise } \\
\hline$<2 \mathrm{hrs} /$ week & 1.00 (Ref.) & & 1.00 (Ref.) & & 1.00 (Ref.) & \\
\hline $2-3.9 \mathrm{hrs} /$ week & $1.21(0.89-1.65)$ & 0.233 & $0.93(0.68-1.28)$ & 0.674 & $1.12(0.84-1.51)$ & 0.435 \\
\hline $4-6.9 \mathrm{hrs} /$ week & $0.89(0.66-1.19)$ & 0.425 & $0.91(0.67-1.24)$ & 0.561 & $1.09(0.83-1.43)$ & 0.555 \\
\hline$\geq 7 \mathrm{hrs} /$ week & $1.17(0.85-1.63)$ & 0.339 & $0.70(0.48-1.03)$ & 0.071 & $0.96(0.70-1.32)$ & 0.816 \\
\hline \multicolumn{7}{|l|}{ TV watching } \\
\hline$<16 \mathrm{hrs} /$ week & 1.00 (Ref.) & & 1.00 (Ref.) & & 1.00 (Ref.) & \\
\hline$\geq 16$ hrs/week & $1.04(0.92-1.18)$ & 0.531 & $0.96(0.88-1.05)$ & 0.556 & $0.94(0.84-1.06)$ & 0.306 \\
\hline \multicolumn{7}{|l|}{ Office work } \\
\hline$<14 \mathrm{hrs} /$ week & 1.00 (Ref.) & & 1.00 (Ref.) & & 1.00 (Ref.) & \\
\hline$\geq 14 \mathrm{hrs} /$ week & $0.95(0.83-1.07)$ & 0.390 & $0.93(0.82-1.05)$ & 0.246 & $1.02(0.91-1.14)$ & 0.765 \\
\hline \multicolumn{7}{|l|}{ Entertainment } \\
\hline$<4 \mathrm{hrs} /$ week & 1.00 (Ref.) & & 1.00 (Ref.) & & 1.00 (Ref.) & \\
\hline$\geq 4 \mathrm{hrs} /$ week & $0.98(0.88-1.10)$ & 0.749 & $0.98(0.88-1.10)$ & 0.774 & $0.97(0.87-1.07)$ & 0.502 \\
\hline
\end{tabular}

HCE and HTN increased by frequent TV watching and office work.

This study has also confirmed previous data showing low levels of PA among the Greek population. Only $1 / 3$ of Greek adults reported walking more than 7 hours per week and the vast majority of the subjects (90\%) reported exercising less than 2 hours per week. In the ATTICA study, half of the studied population of both genders reported being physically inactive. ${ }^{10}$

We herein report that regular walking for more than 2 hours per week was inversely associated with a risk of being overweight and abdominally obese, while walking for more than 7 hours per week was associated with a risk of being totally obese. These associations were found only in men, this discrepancy possibly being explained by the higher metabolic rate (per kg of body weight) of men which is due to their larger lean body mass. ${ }^{16}$ It could be assumed that women need to walk more time than men in order to reduce the risk of excess body fat. In women, only engagement in entertainment activities for more than 4 hours per week was associated with decreased risk of being overweight which, to the best of our knowledge, is a novel finding. It could be attributed to the fact that outdoor activities, such as going out with friends to restaurants, cafés, and bars are linked to a better balance control, thus helping individuals to keep their weight at a lower level. The reverse etiology is also possible, i.e., normal-weighted subjects have more active social life than their obese counterparts.

One of the very limited Greek studies that have 
Table 3. Odds ratio of overweight, obesity and abdominal obesity by different physical activity patterns in women

\begin{tabular}{|c|c|c|c|c|c|c|}
\hline \multirow[b]{2}{*}{ Predictor } & \multicolumn{2}{|l|}{ Overweight } & \multicolumn{2}{|l|}{ Obesity } & \multicolumn{2}{|c|}{ Abdominal obesity } \\
\hline & Odds Ratio (95\%CI) & $\mathbf{P}$ & Odds Ratio (95\%CI) & $\mathbf{P}$ & Odds Ratio (95\%CI) & $\mathbf{P}$ \\
\hline \multicolumn{7}{|l|}{ Age group } \\
\hline $18-39$ & 1.00 (Ref.) & & 1.00 (Ref.) & & 1.00 (Ref.) & \\
\hline $40-65$ & $1.46(1.32-1.62)$ & $<0.001$ & $1.82(1.61-2.06)$ & $<0.001$ & $1.72(1.56-1.89)$ & $<0.001$ \\
\hline$>65$ & $2.13(1.68-2.70)$ & $<0.001$ & $4.57(3.73-5.59)$ & $<0.001$ & $4.71(3.62-6.13)$ & $<0.001$ \\
\hline \multicolumn{7}{|l|}{ Walking } \\
\hline$<2 \mathrm{hrs} /$ week & 1.00 (Ref.) & & 1.00 (Ref.) & & 1.00 (Ref.) & \\
\hline $2-3.9 \mathrm{hrs} /$ week & $0.96(0.83-1.10)$ & 0.535 & $0.97(0.83-1.13)$ & 0.679 & $0.98(0.85-1.12)$ & 0.720 \\
\hline $4-6.9 \mathrm{hrs} /$ week & $1.00(0.86-1.16)$ & 0.994 & $1.06(0.90-1.25)$ & 0.493 & $1.10(0.95-1.27)$ & 0.211 \\
\hline$\geq 7 \mathrm{hrs} /$ week & $0.96(0.85-1.08)$ & 0.482 & $1.05(0.92-1.21)$ & 0.463 & $1.00(0.89-1.12)$ & 0.938 \\
\hline \multicolumn{7}{|l|}{ Exercise } \\
\hline$<2 \mathrm{hrs} /$ week & 1.00 (Ref.) & & 1.00 (Ref.) & & 1.00 (Ref.) & \\
\hline $2-3.9 \mathrm{hrs} /$ week & $1.02(0.82-1.26)$ & 0.855 & $1.01(0.79-1.29)$ & 0.922 & $1.05(0.86-1.29)$ & 0.634 \\
\hline $4-6.9 \mathrm{hrs} /$ week & $0.80(0.61-1.07)$ & 0.131 & $0.95(0.69-1.32)$ & 0.775 & $1.02(0.78-1.32)$ & 0.889 \\
\hline$\geq 7 \mathrm{hrs} /$ week & $0.90(0.59-1.37)$ & 0.626 & $1.43(0.94-2.18)$ & 0.096 & $1.10(0.75-1.61)$ & 0.624 \\
\hline \multicolumn{7}{|l|}{ TV watching } \\
\hline$<16 \mathrm{hrs} /$ week & 1.00 (Ref.) & & 1.00 (Ref.) & & 1.00 (Ref.) & \\
\hline$\geq 16$ hrs/week & $0.95(0.85-1.06)$ & 0.364 & $0.96(0.84-1.09)$ & 0.490 & $0.91(0.79-1.04)$ & 0.254 \\
\hline \multicolumn{7}{|l|}{ Office work } \\
\hline$<14$ hrs/week & 1.00 (Ref.) & & 1.00 (Ref.) & & 1.00 (Ref.) & \\
\hline$\geq 14 \mathrm{hrs} /$ week & $0.94(0.82-1.07)$ & 0.345 & $0.91(0.78-1.07)$ & 0.254 & $0.97(0.86-1.11)$ & 0.688 \\
\hline \multicolumn{7}{|l|}{ Entertainment } \\
\hline$<4$ hrs/week & 1.00 (Ref.) & & 1.00 (Ref.) & & 1.00 (Ref.) & \\
\hline$\geq 4 \mathrm{hrs} /$ week & $0.88(0.79-0.98)$ & 0.025 & $0.92(0.81-1.05)$ & 0.226 & $0.91(0.82-1.01)$ & 0.089 \\
\hline
\end{tabular}

investigated similar issues was conducted in Northern Greece and showed that PA and BMI were negatively associated. ${ }^{17}$ In a European study, the EPIC-PANACEA survey, which was conducted in 9 European countries, it was demonstrated that both PA at work and leisure-time physical activity were inversely correlated with BMI and waist circumference. ${ }^{11}$ Accordingly, most international studies found an inverse relationship between PA and OB..$^{18}$ In fact, regular exercise on a permanent basis can regulate energy balance, body fat and body homeostasis. ${ }^{19} \mathrm{~A}$ recent review that reported on the prevalence of $\mathrm{OB}$ and predisposing factors in Greece from the second World War until today concluded that both sedentary lifestyle and lack of sports and exercise practices contribute to excess body weight. ${ }^{20}$ Walking in particular may reduce the risk of obesity, other cardiometabolic risk factors and cardiovascular disease, and specifically ischemic stroke. ${ }^{21}$

In the second part of our study we examined the relationship between PA patterns and the presence of cardiometabolic risk factors as reported in our population. Notably, prevalence of risk factors in our sample was found to be lower than those reported in similar Greek studies, ${ }^{9,22}$ this possibly due to the screening methodology used to investigate the presence of these comorbidities (proxy, self-reported data) or to the relatively young age of the participants compared to other studies. In a similarly designed US study, ${ }^{23}$ similar rates of T2DM and HCE were found but those of HTN were reported to be higher in comparison to our study.

In men, the risk of HCE and HTN decreased after 
Table 4. Odds ratio of dyslipidemia, diabetes mellitus and hypertension by different physical activity patterns in men

\begin{tabular}{|c|c|c|c|c|c|c|}
\hline \multirow[b]{2}{*}{ Predictor } & \multicolumn{2}{|c|}{ Hypercholesterolemia } & \multicolumn{2}{|c|}{ Diabetes mellitus } & \multicolumn{2}{|c|}{ Hypertension } \\
\hline & Odds Ratio (95\%CI) & $\mathbf{P}$ & Odds Ratio (95\%CI) & $\mathbf{P}$ & Odds Ratio (95\%CI) & $\mathbf{P}$ \\
\hline \multicolumn{7}{|l|}{ Age group } \\
\hline $18-39$ & 1.00 (Ref.) & & 1.00 (Ref.) & & 1.00 (Ref.) & \\
\hline $40-65$ & $2.76(2.14-3.56)$ & $<0.001$ & $2.46(1.61-3.74)$ & $<0.001$ & $4.25(2.93-6.17)$ & $<0.001$ \\
\hline$>65$ & $4.03(2.79-5.84)$ & $<0.001$ & $9.62(5.83-15.88)$ & $<0.001$ & 22.07 (14.38-33.87) & $<0.001$ \\
\hline \multicolumn{7}{|l|}{ Walking } \\
\hline$<2 \mathrm{hrs} /$ week & 1.00 (Ref.) & & 1.00 (Ref.) & & 1.00 (Ref.) & \\
\hline $2-3.9 \mathrm{hrs} /$ week & $1.18(0.97-1.43)$ & 0.100 & $1.02(0.78-1.32)$ & 0.544 & $1.08(0.86-1.37)$ & 0.509 \\
\hline $4-6.9 \mathrm{hrs} /$ week & $1.14(0.92-1.41)$ & 0.220 & $0.88(0.65-1.16)$ & 0.236 & $1.08(0.84-1.40)$ & 0.534 \\
\hline$\geq 7 \mathrm{hrs} /$ week & $0.91(0.77-1.07)$ & 0.250 & $0.79(0.55-1.07)$ & 0.092 & $0.98(0.81-1.18)$ & 0.808 \\
\hline \multicolumn{7}{|l|}{ Exercise } \\
\hline$<2 \mathrm{hrs} /$ week & 1.00 (Ref.) & & 1.00 (Ref.) & & 1.00 (Ref.) & \\
\hline $2-3.9 \mathrm{hrs} /$ week & $0.67(0.42-1.08)$ & 0.098 & $1.04(0.54-1.99)$ & 0.907 & $0.60(0.32-1.11)$ & 0.104 \\
\hline $4-6.9 \mathrm{hrs} /$ week & $0.93(0.62-1.41)$ & 0.733 & $0.30(0.10-0.96)$ & 0.042 & $0.50(0.28-1.00)$ & 0.049 \\
\hline$\geq 7 \mathrm{hrs} /$ week & $0.45(0.23-0.90)$ & 0.023 & $0.60(0.22-1.65)$ & 0.326 & $1.14(0.64-2.05)$ & 0.656 \\
\hline \multicolumn{7}{|l|}{ TV watching } \\
\hline$<16 \mathrm{hrs} /$ week & 1.00 (Ref.) & & 1.00 (Ref.) & & 1.00 (Ref.) & \\
\hline$\geq 16 \mathrm{hrs} / \mathrm{week}$ & $1.20(1.02-1.39)$ & 0.023 & $1.17(0.92-1.49)$ & 0.194 & $1.36(1.14-1.62)$ & 0.001 \\
\hline \multicolumn{7}{|l|}{ Office work } \\
\hline$<14 \mathrm{hrs} /$ week & 1.00 (Ref.) & & 1.00 (Ref.) & & 1.00 (Ref.) & \\
\hline$\geq 14 \mathrm{hrs} / \mathrm{week}$ & $1.55(1.34-1.80)$ & $<0.001$ & $1.12(0.87-1.44)$ & 0.372 & $1.33(1.11-1.59)$ & 0.002 \\
\hline \multicolumn{7}{|l|}{ Entertainment } \\
\hline$<4 \mathrm{hrs} /$ week & 1.00 (Ref.) & & 1.00 (Ref.) & & 1.00 (Ref.) & \\
\hline$\geq 4 \mathrm{hrs} /$ week & $0.93(0.80-1.07)$ & 0.289 & $0.94(0.75-1.18)$ & 0.575 & $0.93(0.79-1.10)$ & 0.409 \\
\hline
\end{tabular}

regular exercise for more than 7 hours per week and 4 hours per week, respectively, and increased with TV watching for more than 16 hours per week and office work for more 14 hours per week. Additionally, the risk of T2DM decreased after exercising for more than 4 hours per week. In women, frequent TV watching increased the risk of HTN and frequent office work decreased the risk of T2DM, while physical activity practices did not affect any of these cardiometabolic factors.

In the ATTICA study, a regional Greek study, physical activity was found to be inversely associated with the cumulative risk factors score of OB, HTN, HCE, and T2DM, in both genders, but not with each risk factor separately. ${ }^{10}$

Similarly, Athyros et al. reported that the prevalence of metabolic syndrome in Greek adults was high $(23.6 \%$ in total; $24.2 \%$ for men and $23.6 \%$ for women) and the majority of the participants reported a sedentary lifestyle, with TV watching being their main entertainment activity (approximately 4 hours per day). ${ }^{9}$

A number of studies have reported that higher levels of PA, especially moderate-intensity exercise, are associated with significant reduction in risk of $\mathrm{T}_{2} \mathrm{DM}^{24}$ and insulin resistance. ${ }^{25}$ Williams showed that exercise intensity is inversely associated with the prevalence of HTN, HCE and T2DM. ${ }^{26}$ The same author found, in another report, that fitter men had lower odds of becoming diabetic, hypercholesterolemic and hypertensive $\left(86 \%, 67 \%, 62 \%\right.$, respectively). ${ }^{27}$ Gill and Cooper presented data from six large-scale interventional trials and showed that adults with impaired glucose tolerance or at high risk of CVD had 
Table 5. Odds ratio of dyslipidemia, diabetes mellitus and hypertension by different physical activity patterns in women

\begin{tabular}{|c|c|c|c|c|c|c|}
\hline \multirow[b]{2}{*}{ Predictor } & \multicolumn{2}{|c|}{ Hypercholesterolemia } & \multicolumn{2}{|c|}{ Diabetes mellitus } & \multicolumn{2}{|c|}{ Hypertension } \\
\hline & Odds Ratio (95\%CI) & $\mathbf{P}$ & Odds Ratio (95\%CI) & $\mathbf{P}$ & Odds Ratio (95\%CI) & $\mathbf{P}$ \\
\hline \multicolumn{7}{|l|}{ Age group } \\
\hline $18-39$ & 1.00 (Ref.) & & 1.00 (Ref.) & & 1.00 (Ref.) & \\
\hline $40-65$ & $2.40(1.98-2.90)$ & $<0.001$ & $1.73(1.29-2.33)$ & $<0.001$ & $3.27(2.60-4.12)$ & $<0.001$ \\
\hline$>65$ & $8.15(6.32-10.50)$ & $<0.001$ & $10.93(7.83-15.25)$ & $<0.001$ & $27.63(21.10-36.18)$ & $<0.001$ \\
\hline \multicolumn{7}{|l|}{ Walking } \\
\hline$<2 \mathrm{hrs} /$ week & 1.00 (Ref.) & & 1.00 (Ref.) & & 1.00 (Ref.) & \\
\hline $2-3.9 \mathrm{hrs} /$ week & $1.18(0.96-1.46)$ & 0.121 & $1.12(0.81-1.54)$ & 0.485 & $0.98(0.77-1.24)$ & 0.845 \\
\hline $4-6.9 \mathrm{hrs} /$ week & $1.10(0.88-1.39)$ & 0.399 & $0.79(0.54-1.16)$ & 0.238 & $1.17(0.91-1.50)$ & 0.216 \\
\hline$\geq 7 \mathrm{hrs} /$ week & $0.83(0.68-1.02)$ & 0.079 & $0.89(0.66-1.19)$ & 0.426 & $1.07(0.87-1.32)$ & 0.529 \\
\hline \multicolumn{7}{|l|}{ Exercise } \\
\hline$<2 \mathrm{hrs} /$ week & 1.00 (Ref.) & & 1.00 (Ref.) & & 1.00 (Ref.) & \\
\hline $2-3.9 \mathrm{hrs} /$ week & $0.82(0.56-1.21)$ & 0.316 & $0.46(0.20-1.04)$ & 0.062 & $0.64(0.40-1.03)$ & 0.069 \\
\hline $4-6.9 \mathrm{hrs} /$ week & $0.61(0.34-1.10)$ & 0.103 & $0.87(0.38-1.98)$ & 0.739 & $0.83(0.46-1.50)$ & 0.535 \\
\hline$\geq 7 \mathrm{hrs} /$ week & $1.17(0.61-2.26)$ & 0.636 & $1.66(0.67-4.11)$ & 0.277 & $0.60(0.22-1.64)$ & 0.320 \\
\hline \multicolumn{7}{|l|}{ TV watching } \\
\hline$<16$ hrs/week & 1.00 (Ref.) & & 1.00 (Ref.) & & 1.00 (Ref.) & \\
\hline$\geq 16$ hrs/week & $1.13(0.95-1.35)$ & 0.159 & $1.10(0.85-1.42)$ & 0.465 & $1.33(1.11-1.60)$ & 0.002 \\
\hline \multicolumn{7}{|l|}{ Office work } \\
\hline$<14$ hrs/week & 1.00 (Ref.) & & 1.00 (Ref.) & & 1.00 (Ref.) & \\
\hline$\geq 14$ hrs/week & $0.95(0.76-1.19)$ & 0.665 & $0.64(0.42-0.97)$ & 0.034 & $0.81(0.63-1.06)$ & 0.121 \\
\hline \multicolumn{7}{|l|}{ Entertainment } \\
\hline$<4 \mathrm{hrs} /$ week & 1.00 (Ref.) & & 1.00 (Ref.) & & 1.00 (Ref.) & \\
\hline$\geq 4$ hrs/week & $0.96(0.79-1.16)$ & 0.665 & $0.89(0.66-1.21)$ & 0.465 & $0.89(0.72-1.10)$ & 0.268 \\
\hline
\end{tabular}

a decreased risk of diabetes upon moderate increase of PA by approximately 150 minutes per week, and the effect was greater if accompanied by weight loss. ${ }^{28}$ The reverse association, e.g. people with metabolic risk factors tend to exercise more, could also occur, but it seems less probable.

A recent review by Katzmarzyk and Lear demonstrated that physical activity had only a modest effect on chronic disease risk factors in obese individuals. ${ }^{29}$ Thus, after introducing exercise, six out of ten research groups reported a statistically significant reduction in diastolic blood pressure, eight out of ten in systolic blood pressure and only two out of nine found a reduction in fasting insulin. Most of the studies showed improvements in blood lipid levels (LDL-C, HDL-C, TGs). ${ }^{29}$
The correlation of walking with the risk of metabolic comorbidities was less evident. More than 7 hours of walking per week were needed to establish a lower risk of HCE.

As far as sedentary behaviours are concerned, in our study, both frequent TV watching and office work increased the risk of HCE and HTN in men, while in women, TV watching increased only the risk of HTN. Healy et al. ${ }^{30}$ indicated a detrimental association of time spent in TV watching with waist circumference, systolic blood pressure and 2-h plasma glucose in both men and women, and with fasting plasma glucose, triglycerides and HDL-C only in women. ${ }^{30}$ Recently, Thorp et al. provided evidence that time spent on TV watching was detrimentally associated with all cardiometabolic risk biomarkers. ${ }^{31}$ 
TV watching leads to harmful habits such as passive snacking and lust for sugar-sweetened soft drinks and energy-dense foods. ${ }^{32}$ It causes lower metabolic rate in comparison with other sedentary activities like sewing, playing board games, driving a car, reading and writing. ${ }^{33}$ Finally, the relation between TV watching and metabolic diseases could be partly attributed to the psychological stress induced by $\mathrm{TV}$, which enhances insulin resistance, sympathetic system activation, visceral adiposity and metabolic syndrome.

Notably, the aforementioned associations between physical activity, sedentary lifestyle patterns and cardiometabolic risk factors were observed almost exclusively in the male gender. This specific finding has also been highlighted in some recent epidemiological studies and principally concerns the negative relationship between TV watching, office work and cardiometabolic parameters. ${ }^{34,35}$ It is possible that molecular metabolic pathways active in men during physical activity are more closely related to cardiometabolic risk factors or it may simply be the result of over-reporting of PA (or underreporting of sedentary behaviours) by the women. ${ }^{36}$ One finding that needs to be underlined is the differentiated gender effect on cardiometabolic factors that was produced by office work. In men, frequent office work increased the risk of HCE and HTN, while in women it was associated with decreased risk of T2DM. It is possible that office work in women is expressed via higher activity levels in contrast to men, who tend to be more sedentary in this setting.

Some limitations of our study have to be mentioned. Anthropometric measurements in the study population were performed by adolescents 13-19 years old who were trained by school instructors. Although the adolescents were thoroughly trained for this purpose, this is not a validated survey method. Also, the presence of cardiometabolic comorbidities was based on self-report and could not be verified. However, the major strength of this study is that it is the first large-scale survey ever conducted across the country, which allows the evaluation of the association of $\mathrm{OB}$ and its comorbidities with PA and sedentary lifestyle, albeit in a non-representative manner.

In conclusion, the present study is the first report of a Greek population-based study to show that walking activity in adults, and particularly in men, was significantly associated with low risk for obesity status, while frequent exercise practices and lower sedentary behaviour were associated with reduced risk for cardiometabolic factors, mainly hypercholesterolemia and hypertension. Our data call attention to the need for the implementation of effective interventions that should combine: a) restrictions of sedentary behaviours, such as staying indoors, TV watching, playing computer games or motorized transport, and b) increase of outdoor activities such as sports, walking, bicycling, climbing stairs and entertainment activities. The study of exercise and leisure activity patterns and their determinants could provide information on specific population subgroups that are at risk for developing OB and associated comorbidities. Thus, public health programs should take these factors into consideration when planning strategies for the prevention and management of OB and its comorbidities.

\section{REFERENCES}

1. National Task Force on the Prevention and Treatment of Obesity, 2000 Overweight and health risk. Arch Intern Med 160: 898-904.

2. World Health Organisation, 2000 Obesity: Preventing and Managing the Global Epidemic. Report of a WHO consultation. WHO Technical Report Series 894. Geneva: World Health Organization.

3. Cecchini M, Sassi F, Lauer JA, et al, 2010 Tackling of unhealthy diets, physical inactivity, and obesity: health effects and cost-effectiveness. The Lancet 376: 17751784.

4. Paffenbarger RSJ, Hyde RT, Wing AL, Hsieh CC, 1986 Physical activity, all-cause mortality and longevity of college alumni. N Engl J Med 314: 605-613.

5. Health Education Authority, 1995 Promoting physical activity. London: Health Education Authority.

6. Hancox RJ, Milne BJ, Poulton R, 2004 Association between child and adolescent television viewing and adult health: A longitudinal birth cohort study. Lancet 364: 257-262.

7. Blair SN, Morris JN, 2009 Healthy Hearts- and the Universal Benefits of being physically active: Physical activity and health. Ann Epidemiol 19: 253-256.

8. Roberts CW, 1997 Floating in Fat: Fat kids and Fat Adults. Am J Cardiol 80: 1117-1119.

9. Athyros VG, Ganotakis ES, Bathianaki M, et al, 2005 MetS-Greece Collaborative Group. The prevalence of the metabolic syndrome in Greece: The MetS-Greece Multicentre Study. Diabetes Obes Metab 7: 397-405. 
10. Pitsavos C, Panagiotakos DB, Lentzas Y, Stefanadis C, 2005 Epidemiology of leisure-time physical activity in socio-demographic, lifestyle and psychological characteristics of men and women in Greece: the Attica Study. BMC Public Health 5: 37-45.

11. Besson H, Ekelund U, Luan J, 2009 A cross-sectional analysis of physical activity and obesity indicators in European participants of the EPIC-PANACEA study. Int J Obes 33: 497-506.

12. Kapantais E, Tzotzas T, Ioannidis I, et al, 2006 First National epidemiological survey on the prevalence of obesity and abdominal fat distribution in Greek adults. Ann Nutr Metab 50: 330-338.

13. Tzotzas T, Vlahavas G, Papadopoulou SK, et al, 2010 Marital status and educational level associated to obesity in Greek adults: Data from the National Epidemiological Survey. BMC Public Health 10: 732-738.

14. Anonymous 2001 Executive Summary of the Third Report of the National Cholesterol Education Program (NCEP) Expert Panel on Detection, Evaluation, and Treatment of High Blood Cholesterol In Adults (Adult Treatment Panel III) JAMA 285: 2486-2497.

15. Aadahl M, von Huth Smith L, Pisinger C, et al, 2009 Five-year change in physical activity is associated with changes in cardiovascular disease risk factors. The Inter99 study. Prev Med 48: 326-331.

16. Cunningham JJ, 1991 Body composition as a determinant of energy expenditure: a synthetic review and a proposed general prediction equation. Am J Clin Nutr 54: 963-969.

17. Tzotzas T, Konstantinidis T, Bougoulia M, Krassas GE, 2004 Factors associated with body mass index in adults from Northern Greece. Hormones (Athens) 3: 111-119.

18. McInnis K, 2000 Exercise and obesity. Coron Artery Dis 11: 111-116.

19. Tremblay A, Therrien F, 2006 Physical activity and body functionality: implications for obesity prevention and treatment. Can J Physiol Pharmacol 84: 149-156.

20. Roditis ML, Parlapani ES, Tzotzas T, et al, 2009 Epidemiology and Predisposing Factors of Obesity in Greece: From the Second World War Until Today. J Pediatr Endocrinol Metab 22: 389-405.

21. Boone-Heinonen J, Evenson KR, Taber DR, GordonLarsen P, 2009 Walking for prevention of cardiovascular disease in men and women: a systematic review of observational studies. Obes Rev 10: 204-217.

22. Pitsavos C, Panagiotakos DB, Chrysohoou C, Stefanadis C, 2003 Epidemiology of cardiovascular risk factors in Greece: aims, design and baseline characteristics of the ATTICA study. BMC Public Health 3: 32-40.
23. Paeratakul S, Lovejoy JC, Ryan DH, Bray GA, 2002 The relation of gender, race and socioeconomic status to obesity and obesity comorbidities in a sample of US adults. Int J Obes 26: 1205-1210.

24. Hu G, Lindström J, Valle TT, et al, 2004. Physical activity, body mass index, and risk of type 2 diabetes in patients with normal or impaired glucose regulation. Arch Intern Med 164: 892-896.

25. Ford ES, Li C, Zhao G, et al, 2010 Sedentary behavior, physical activity, and concentrations of insulin among US adults. Metabolism 59(9): 1268-1275.

26. Williams PT, 2008 Relationship of running intensity to hypertension, hypercholesterolemia, and diabetes. Med Sci Sports Exerc 40: 1740-1748.

27. Williams PT, 2008 Vigorous exercise, fitness and incident hypertension, high cholesterol, and diabetes. Med Sci Sports Exerc 40: 998-1006.

28. Gill JM, Cooper AR, 2008 Physical activity and prevention of type 2 diabetes mellitus. Sports Med 38: 807-824.

29. Katzmarzyk PT, Lear SA, 2012 Obesity Treatment/ Obesity Comorbidity. Physical activity for obese individuals: a systematic review of effects on chronic disease risk factors. Obes Rev 13: 95-105.

30. Healy GN, Dunstan DW, Salmon J, et al, 2008 Television time and continuous metabolic risk in physically active adults. Med Sci Sports Exerc 40: 639-645.

31. Thorp AA, Healy GN, Owen N, et al, 2010 Deleterious associations of sitting time and television viewing time with cardiometabolic risk biomarkers: Australian Diabetes, Obesity and Lifestyle (AusDiab) study 20042005. Diabetes Care 33: 327-334.

32. Dulloo AG, Antic V, Yang Z, Montani J-P, 2006 Propellers of growth trajectories to obesity and the metabolic syndrome. Int J Obes 30: Suppl 4: 1-3.

33. Ainsworth BE, Haskell WL, Leon AS, et al, 1993 Compendium of physical activities: classification of energy costs of human physical activities. Med Sci Sports Exerc 25: 71-80.

34. Pinto Pereira SM, Ki M, Power C, 2012 Sedentary behaviour and biomarkers for cardiovascular disease and diabetes in mid-life: the role of television-viewing and sitting at work. PLoS One 7: e31132.

35. Stamatakis E, Hamer M, Mishra GD, 2012 Early adulthood television viewing and cardiometabolic risk profiles in early middle age: results from a population, prospective cohort study. Diabetologia 55: 311-320.

36. Shephard RJ, 2003 Limits to the measurement of habitual physical activity by questionnaires. Br J Sports Med 37: 197-206. 